\title{
EXPERIMENTAL VERIFICATION AND STABILITY STATE SPACE ANALYSIS OF CLL-T SERIES PARALLEL RESONANT CONVERTER WITH FUZZY CONTROLLER
}

\author{
Chinnadurai Nagarajan — Muthusamy Madheswaran *
}

\begin{abstract}
This paper presents a closed loop CLL-T (capacitor inductor inductor) series parallel resonant converter (SPRC) has been simulated and the performance is analyzed. A three element CLL-T SPRC working under load independent operation (voltage type and current type load) is presented in this paper.

The stability and AC analysis of CLL-T SPRC has been developed using state space technique and the regulation of output voltage is done by using Fuzzy controller. The simulation study indicates the superiority of fuzzy control over the conventional control methods. The proposed approach is expected to provide better voltage regulation for dynamic load conditions. A prototype $300 \mathrm{~W}, 100 \mathrm{kHz}$ converter is designed and built to experimentally demonstrate, dynamic and steady state performance for the CLL-T SPRC are compared from the simulation studies.
\end{abstract}

K e y w o r d s: resonant converter, fuzzy logic, control system, power electronics, MATLAB

\section{INTRODUCTION}

The developments of the DC-DC Resonant Converters are increasing now a day due its performance.DCDC Resonant Converter (RC) are used in telecommunication and aerospace application, at high frequency these converters experience high switching losses, reduced reliability, electromagnetic interference (EMI) and acoustic noise. To over come these drawbacks, the series parallel resonant converters (SPRC) is found to be suitable, due to various inherent advantages. The series and parallel resonant converter (SRC and PRC respectively) circuits are the basic resonant converter topologies with two reactive elements. The merits of SRC include better load efficiency and inherent dc blocking of the isolation transformer due to the series capacitor in the resonant network. However, the load regulation is poor and output-voltage regulation at no load is not possible by switching frequency variations. On the other hand, PRC offers no-load regulation but suffers from poor load efficiency and lack of dc blocking for the isolation transformer. It has been suggested to design Resonant Converter with three reactive components for better regulation. The LCL tank circuit based DC-DC SPRC has been experimentally demonstrated and reported by many researchers [1-4]. Mangesh B. Borage et al [5] have demonstrated the characteristics of LCL-T Resonant converter using Asymmetrical duty cycle (ADC).The converter operated at fixed resonant frequency and its analysised using state space approach. Later, Mangesh Borage et al [6] have demonstrated an LCL-T half bridge resonant converter with clamp diodes. The output current or voltage is sensed for every change in load because the output voltage or constant current increases linearly. The feed back control circuit has not been provided. LCL-T RC with constant current supply operated at resonant frequency is presented [7].

Vijayakumar Belaguli et al [8], has experimentally demonstrated with independent load when operated at resonant frequency, making it attractive for application as a constant voltage $(\mathrm{CV})$ power supply. It has been found from the literature that the LCL tank circuit connected in series-parallel with the load and operated in above resonant frequency improves the load efficiency and independent operation. Chew et al [9] have demonstrated LCC SPRC using robust control method, this method used to varying the converter gain, the gain was derived by using state plan analysis. The voltage and current type load was presented with variable load condition. The closed loop operation was presented using PI controller with load independent operation as obtained. Lakshminarasamma et al [10] have demonstrated active clamp ZVS DC-DC converter. The steady state stability analysis was presented for ZVS Buck converter. There is no possible of load independent operation. The converter operates at duty cycle $>0.5$, above its operation the converter fails to instability. Later, Martin P. Foster [11] have demonstrated CLL half bridge resonant converter with open loop operation. The ac equivalent circuit analysis and fundamental mode approximation (FMA) analysis was derived used to the modeling the converter and compared. The evaluation of static and dynamic performance was not provided.

Paolo Mattavelli [12] has demonstrated different approaches which offer the fuzzy logic control (FLC). This control technique relies on the human capability to understand the systems behavior and is based on qualitative control rules. The FLC approach with same control rules can be applied to several dcdc converters. However, some scale factors must be tuned according to converter

\footnotetext{
* Centre for Advanced Research, Muthayammal Engineering College, Rasipuram, Tamilnadu, India, nagaraj2k1@gmail.com
} 


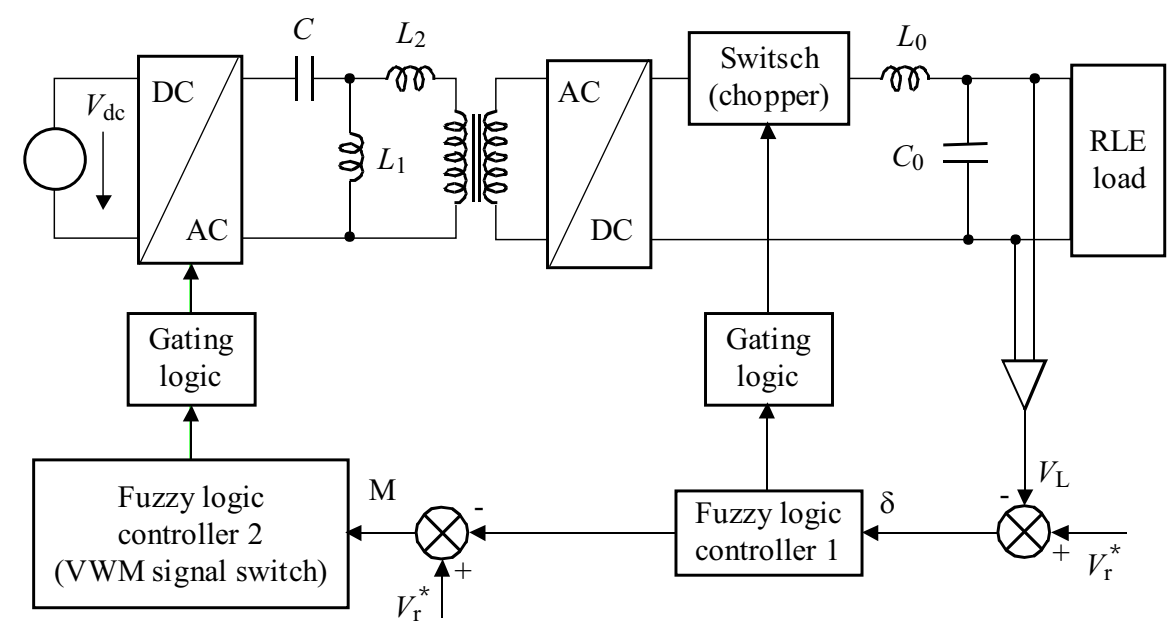

Fig. 1. Block Diagram of CLL-T series parallel resonant converter

topology and parameters. The author utilized the proposed control technique for Buck-Boost converter and demonstrated. J.M. Correa et al [13] have demonstrated a DC/AC series resonant converter with fixed load value considering two control approaches.

Later T.S. Sivakumaran et al [14] have demonstrated a CLC SPRC using FLC for load regulation and line regulation. The performance of controller has been evaluated and found that the load independent operation may not be possible. C. Nagarajan et al [15], have simulated an LCL-T SPRC using FLC and PID controller. The performance of controller has been found to be better when the fuzzy controller has been considered. The Harmonic Spectrum and dynamic analysis for RLE load are presented. M. Prabhakar et al [16] have simulated an LCC RC.closed form expression are derived for different resonant topologies. The Voltage gain expression for these topologies are obtained and plotted.

It is clear from the above literatures that the output voltage regulation of the converter against load and supply voltage fluctuations have important role in designing high-density power supplies. CLL-T SPRC is expected the speed of response, voltage regulation and better load independent operation. Keep the above facts in view, the CLL-T SPRC has been module and analysised for estimating various responses. The closed loop state space module and $\mathrm{AC}$ analysis has been derived and simulate using MATLAB/Simulink. A prototype $300 \mathrm{~W}, 100 \mathrm{kHz}$ the CLL-T SPRC is implemented and the experiment results are compared with the simulation results. The simulation results agree with the experimental results.

\section{PROPOSED CLL-T SERIES PARALLEL RESONANT CONVERTER WITH FUZZY CONTROL CIRCUIT}

The resonant tank consisting of three reactive energy storage elements (CLL-T) has over come the conventional resonant converter that has only two reactive energy storage elements. The first stage converts a dc voltage to a high frequency ac voltage. The second stage of the converter is to convert the ac power to dc power by suitable high frequency rectifier and filter circuit. Power from the resonant circuit is taken either through a transformer in series with the resonant circuit or series in the capacitor comprising the resonant circuit as shown in Fig. 1. In both cases the high frequency feature of the link allows the use of a high frequency transformer to provide voltage transformation and ohmic isolation between the dc source and the load.

In CLL-T SPRC the load voltage can be controlled by varying the switching frequency or by varying the phase difference between the two inverts where the switching frequency of each is fixed to the resonant frequency. The phase domain control scheme is suitable for wide variation of load condition because the output voltage is independent of load. The dc current is absent in the primary side of the transformer, there is no possibility of current balancing. Another advantage of this circuit is that the device currents are proportional to load current. This increases the efficiency of the converter at light loads to some extent because the device losses also decrease with the load current. If the load gets short at this condition, very large current would flow through the circuit. This may damage the switching devices. To make the circuit short circuit proof, the operating frequency should be changed.

A schematic diagram of full-bridge CLL-T SPRC is shown in Fig. 2. The resonant circuit consist of series inductance $\mathrm{L}_{1}$, parallel capacitor $\mathrm{C}$ and series inductance $\mathrm{L}_{2}$. S1-S4 is switching devices having base /gate turn-on and turn-off capability. $\mathrm{D}_{1}$ to $\mathrm{D}_{4}$ are anti-parallel diodes across these switching devices. The MOSFET $\left(S_{1}\right)$ and its anti parallel diode $\left(D_{1}\right)$ act as a bidirectional switch. The gate pulses for $S_{1}$ and $S_{2}$ are in phase but 180 degree out of phase with the gate pulses for $S_{3}$ and $S_{4}$. The positive portion of switch current flows through the MOSFET and negative portion flows through the antiparallel diode. The RLE load is connected across bridge rectifier via $\mathrm{L}_{0}$ and $\mathrm{C}_{0}$. The voltage across the point $\mathrm{AB}$ is rectified and fed to RLE load through $\mathrm{L}_{0}$ and $\mathrm{C}_{0}$. For 


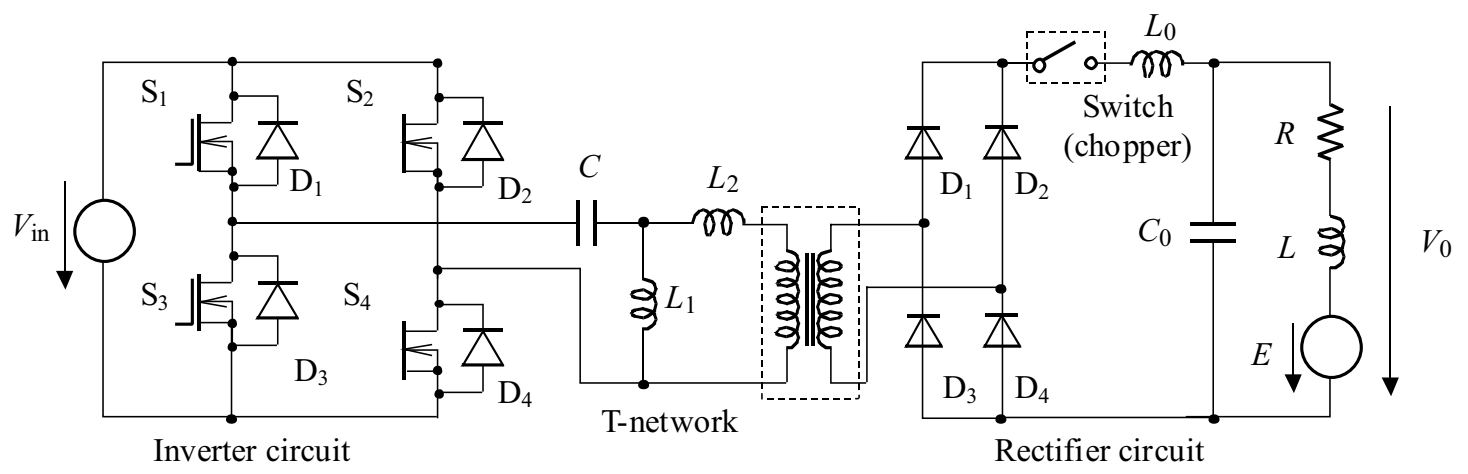

Fig. 2. CLL-T SPRC Resonant Converter

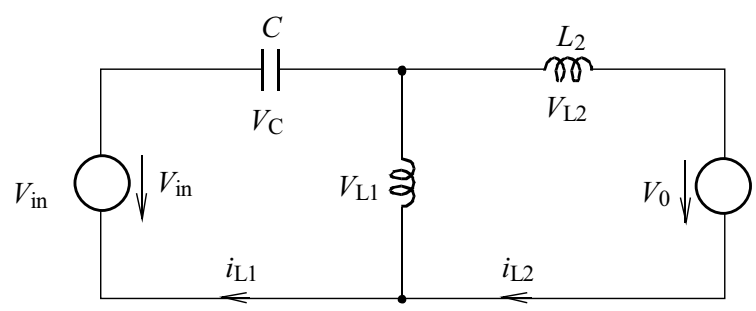

Fig. 3. Equivalent circuit model of CLL T SPRC

the analysis it is assumed that the converter operates in the continuous conduction mode and the semiconductors have ideal characteristics.

\section{STABILITY AND AC ANALYSIS FOR THE PROPOSED CONVERTER}

\subsection{Mathematical Modeling Using State Space Technique}

The equivalent circuit of CLL-T SPRC is shown in Fig. 3.The mathematical modeling using state space technique can be obtained assuming all the components to be ideal.

The state space equation for CLL-T SPRC converter is

$$
\begin{aligned}
\frac{\mathrm{d} i_{L 1}}{\mathrm{~d} t} & =\frac{V_{C}}{L_{1}}-\frac{V_{i n}}{L_{1}}, \\
\frac{\mathrm{d} i_{L 2}}{\mathrm{~d} t} & =\frac{V_{C}}{L_{2}}-\frac{V_{i n}}{L_{1}}-\frac{V_{0}}{L_{2}}, \\
\frac{\mathrm{d} V_{C}}{\mathrm{~d} t} & =\frac{i_{L 1}}{C}+\frac{i_{L 2}}{C} .
\end{aligned}
$$

The state-space model for CLL-T SPRC

$$
\begin{aligned}
\frac{\mathrm{d}}{\mathrm{d} t}\left[\begin{array}{c}
i_{L 1} \\
i_{L 2} \\
V_{C}
\end{array}\right]=\left[\begin{array}{ccc}
0 & 0 & \frac{1}{L 1} \\
0 & 0 & \frac{1}{L 2} \\
\frac{1}{C} & \frac{1}{C} & 0
\end{array}\right] & {\left[\begin{array}{c}
i_{L 1}(t) \\
i_{L 2}(t) \\
V_{C}(t)
\end{array}\right] } \\
& +\left[\begin{array}{cc}
-\frac{1}{L 1} & 0 \\
-\frac{1}{L 1} & -\frac{1}{L 2} \\
0 & 0
\end{array}\right]\left[\begin{array}{c}
V_{i n} \\
V_{0}
\end{array}\right] .
\end{aligned}
$$

\subsection{AC analysis for the proposed converter}

The converter is operated only in the lagging power factor mode, AC sinusoidal analysis has been carried out to bring out the important features of the network. Also, in the ac analysis, the output rectifier and filter are replaced by the equivalent ac resistance and the squarewave input voltage source is replaced by its fundamental sinusoidal equivalent. The power transfer from input to output is assumed to be only via the fundamental component and the contribution of all the harmonics is neglected. Without losing generality, the turns ratio $\left(N_{1} / N_{2}\right)$ of the isolation transformer is assumed to be unity. The equivalent ac resistance for the rectifier with capacitive filter is given by

$$
R_{a c}=\frac{8}{\pi^{2}} R_{0}
$$

The resonant frequency and the normalized switching frequency are defined as

$$
\omega_{r}=\frac{1}{\sqrt{L C}}, f_{r}=\frac{1}{2 \pi \sqrt{L C}}, \omega_{n}=\frac{\omega_{s}}{\omega_{r}}, f_{n}=\frac{f_{s}}{f_{r}} .
$$

The characteristics impedance and $Q$ of the resonant network are

$$
Z=\sqrt{\frac{L}{C}} \text { and } Q=\frac{\omega_{r} L}{R_{0}}=\frac{Z}{R_{0}} .
$$

The ratio of inductance is defined as

$$
\delta=\frac{L_{2}}{L_{1}} .
$$

The voltage and current gain are defined as

$$
M=\frac{V_{0}}{V_{i n}} \text { and } H=\frac{I_{0}}{\left(V_{i n} / Z\right)} .
$$

Voltage gain for the converter topology is computed by using equation (3), from the voltage gain expression, a characteristics plot is obtained. This is compared with the desired characteristics plot to decide upon the suitability for automotive application.

$$
\begin{aligned}
M & =\frac{V_{0}}{V_{i n}}=\frac{1}{\left(1-\frac{1}{\omega_{n}}\right)+j \frac{\pi^{2}}{8} Q\left(\delta \omega_{n}-\frac{1}{\omega_{n}}(1+\delta)\right)}, \\
H & =\frac{1}{\frac{1}{Q}\left(1-\frac{1}{\omega_{)} n}\right)+j \frac{\pi^{2}}{8}\left(\delta \omega_{n}-\frac{1}{\omega_{n}}(1+\delta)\right)} .
\end{aligned}
$$




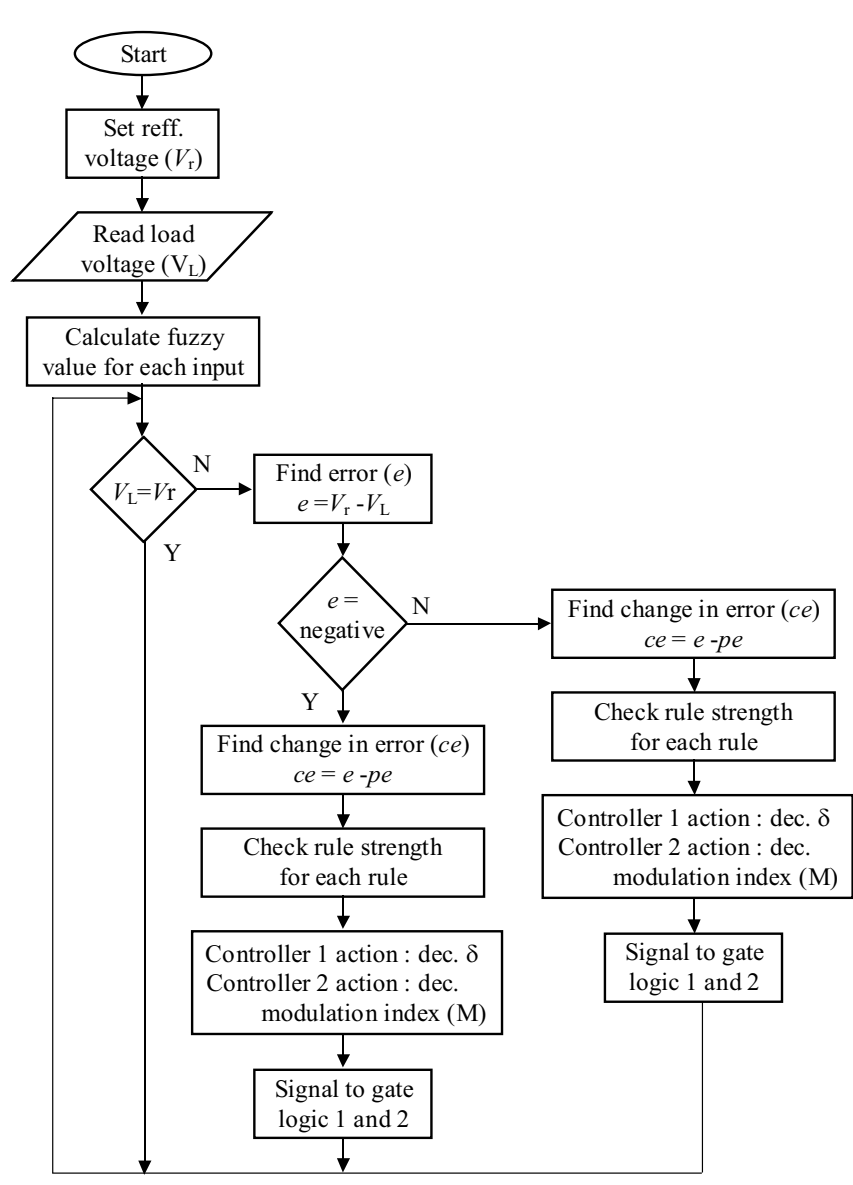

Fig. 4. Flowchart for the FLC

\section{RESULTS AND DISCUSSION}

\subsection{Design parameters of the converter}

For the design of CLL-T SPRC [5], the design specifications are: minimum and maximum value of dc voltage, maximum output current $\left(I_{o}\right)$, corresponding to the full-load condition and switching frequency $(f s)$. In the analysis of previous sections, the transformer turns ratio $\left(N_{1} / N_{2}\right)$ was assumed to be unity. It is desired to design the converter with the following specifications as shown in Table 1.

The values used for all the elements are presented. These values were obtained using a design procedure to assure the resonance for almost all power range (loadindependent design) and also to limit the current and voltage peak values. To prove the wide load range operation and also to show that the fuzzy controller used is robust to parameter variations. The simulation and implementation are carried out for $300 \mathrm{~W}$ load power. The load used on the tests is composed of a series connection of a resistor and a small inductor.

\subsection{Fuzzy Logic Control (FLC)}

Fuzzy control involves three stages: fuzzification, inference or rule evaluation and defuzzification.SPRC is modeled using Mat lab software. Fuzzy control is developed using the fuzzy toolbox. The fuzzy variables $e$, ce and $\Delta u$ are described by triangular membership functions. Five triangular membership functions are chosen for simplicity. Table 2 shows the fuzzy rule base created in the present work based on intuitive reasoning and experience. Fuzzy memberships NB, NS, Z, PS, PB are defined as negative big, negative small, zero, positive small, and positive.

The control rules that relate the fuzzy output to the fuzzy inputs are derived from general knowledge of the system behavior, perception and experience. It can inferred that the output voltage is far from the reference value, then the change of switching frequency $(\Delta u)$ must be large so as to bring the output to the reference value quickly. The output voltage approaches the reference value, and then a small change of switching frequency is necessary and if the output voltage is near the reference value and is approaching it rapidly, then the frequency must be kept constant so as to prevent overshoot. It is also seen that if the output voltage changes even after reaching the reference value then the change of frequency must be changed by a small amount to prevent the output from moving away.

Table 1. Design Parameters

\begin{tabular}{ll}
\hline \multicolumn{1}{c}{ Parameter } & Value \\
\hline Power output & $300 \mathrm{~W}$ \\
Minimum input voltage & $100 \mathrm{~V}$ \\
Minimum output voltage & $100 \mathrm{~V}$ \\
Maximum load current & $3 \mathrm{~A}$ \\
Transformer Turns ratio & 1 \\
Switching frequency $\left(f_{s}\right)$ & $100 \mathrm{KHz}$ \\
Series Inductance $\mathrm{L}_{1}, \mathrm{~L}_{2}$ & $39.18 \mu \mathrm{H}$ \\
Parallel Capacitance $(\mathrm{C})$ & $66 \mathrm{nF}$ \\
Load Inductance $\left(\mathrm{L}_{o}\right)$ & $1 \mathrm{mH}$ \\
Load Capacitance $\left(\mathrm{C}_{o}\right)$ & $650 \mu \mathrm{F}$ \\
\hline
\end{tabular}

Table 2. Fuzzy Rules

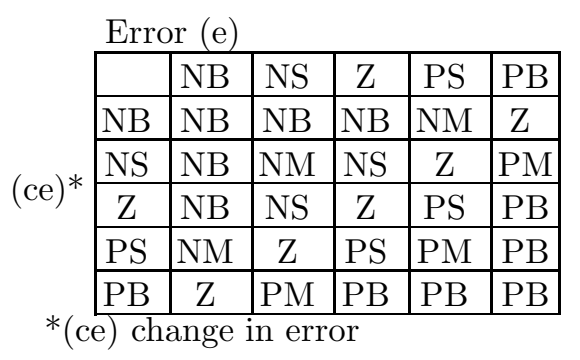

At every sampling interval, the reference voltage and load voltage are used to calculate the error (e) and change in error (ce) signals that act as the input to the FLC. The stage of fuzzification, fuzzy inference and defuzzification are then performed as given flowchart shown in Fig. 4.

$$
\begin{aligned}
e & =V_{r}-V_{L}, \\
c e & =e-p e
\end{aligned}
$$



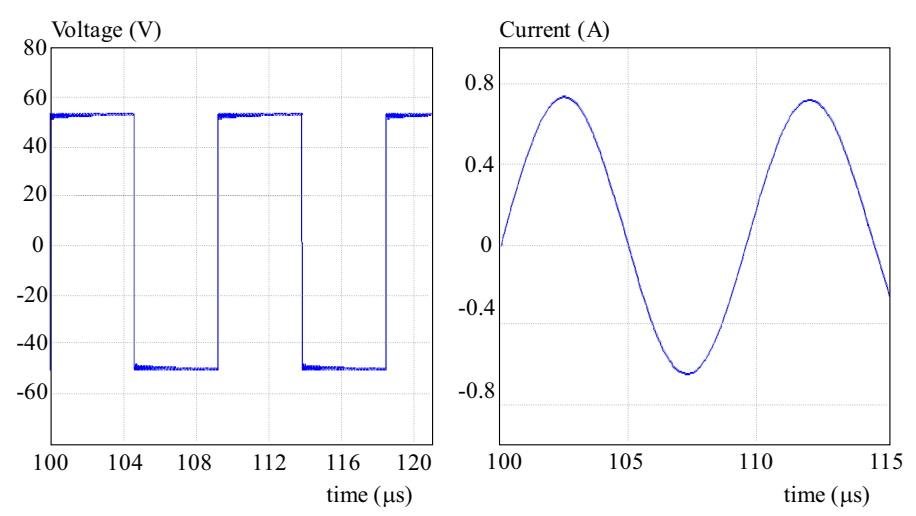

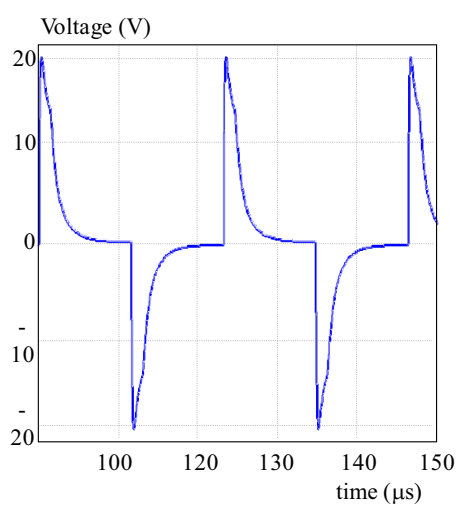

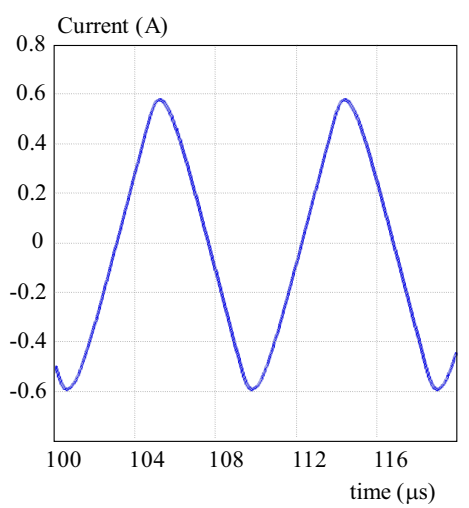

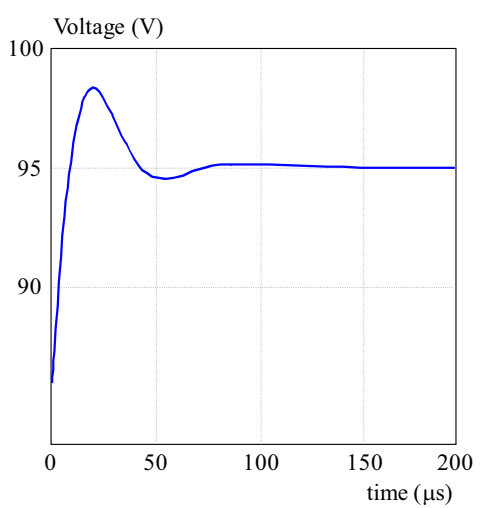

Fig. 5. (a)- inverter voltage $\left(V_{A B}\right)$, (b) - inverter current (transformer primary side), (c) - voltage across capacitor, (d) - current through inductance $L_{1}$, (e) - output voltage fed RLE load for $V_{r}=100 \mathrm{~V}$

Table 3. Evaluation of transient and steady state performances by using FLC

\begin{tabular}{cccc}
\hline Controller & Settling Time in Sec & $\%$ Over Shoot & Steady state error \\
\hline Open loop & 0.45 & 1.05 & 0.04 \\
Closed Loop (FLC) & 0.12 & $1.8 \mathrm{~V}$ & 0.004 \\
\hline
\end{tabular}

where $V_{r}$ is the reference or the desired output voltage, $V_{L}$ is the actual output voltage and pe is previous error. The duty ratio of the converter can be determined by the fuzzy inference. For instance, if the output voltage continues to increase gradually while the current is low during the charging process the fuzzy controller will maintain increase in voltage to reach the set point. A drop in the output voltage level triggers the fuzzy controller to increase the output voltage of the converter by modifying the modulation index (MI) of the converter. The resolution of fuzzy logic control system relies on the fuzziness of the control variables while the fuzziness of the control variables depends on the fuzziness of their membership functions.

\subsection{Simulation Results}

The Closed loop simulation using FLC is carried out using MATLAB/Simulink software. Depending on error and the change in error, the value of change of switching frequency is calculated. The Fuzzy set parameters instruction and function blocks available in MATLAB are used to update the new switching frequency of the pulse generators. The entire system is simulated with a switching frequency of $100 \mathrm{KHz}$. The converter Resonant voltage, Resonant current and output load voltage are shown in Fig. 5a-5e.

The inductor and capacitor are connected to the output of inverter for resonance purpose and it is used for impedance matching, current control. Another good feature of this converter is that the converter operation is not affected by the non ideality of the output transformer (magnetizing inductance) because of the additional resonance inductor $L_{2}$. The output voltage is constant for any load variation.

The output voltage are high, it is observed that the settling time $0.12 \mathrm{sec}$. The slight droop in the resonant characteristics is due to the increase in conduction losses in the bridge inverter and resonant network. The result is justified that settling time of output voltage in CLL-T SPRC controller is more than that of the settling time. The output voltage response is flexible and sensitive.

It is clear that the CLL-T SPRC is ineffective in eliminating the overshoot, rise time and high frequency noise suppression. This happens because of several reasons. The 

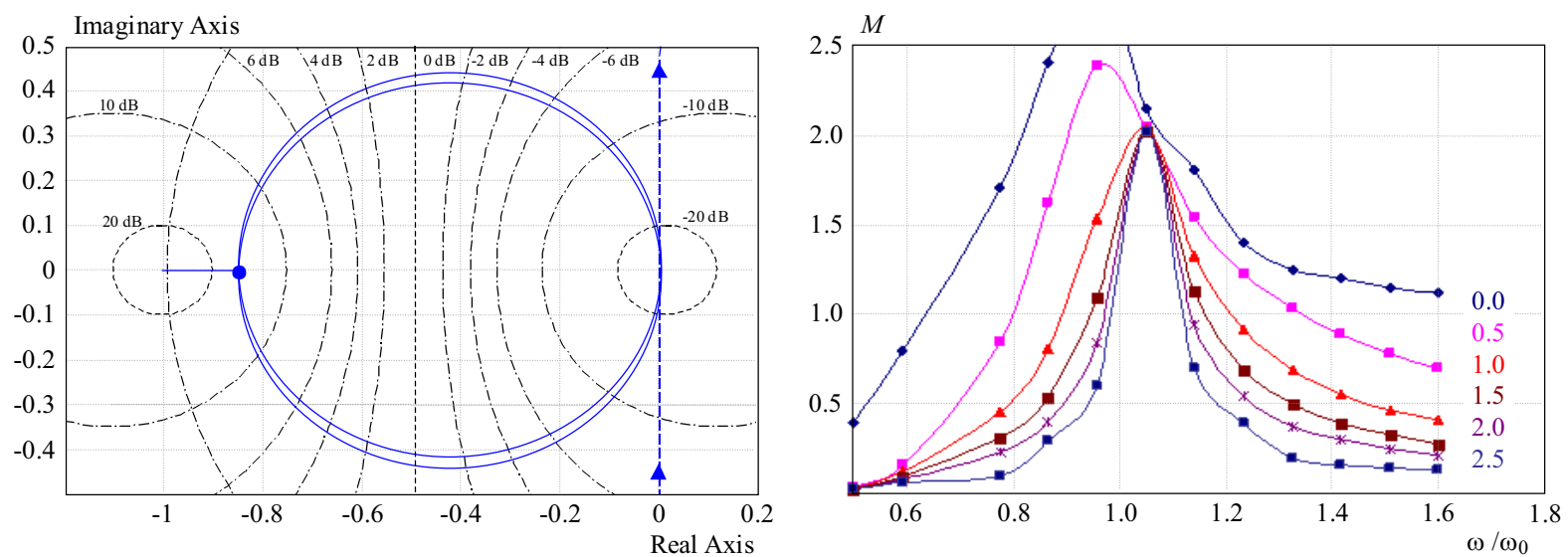

Fig. 6. (a) Stability analysis of CLL-T SPRC, (b) voltage gain versus $\omega_{S} / \omega_{T}$ for different $Q$
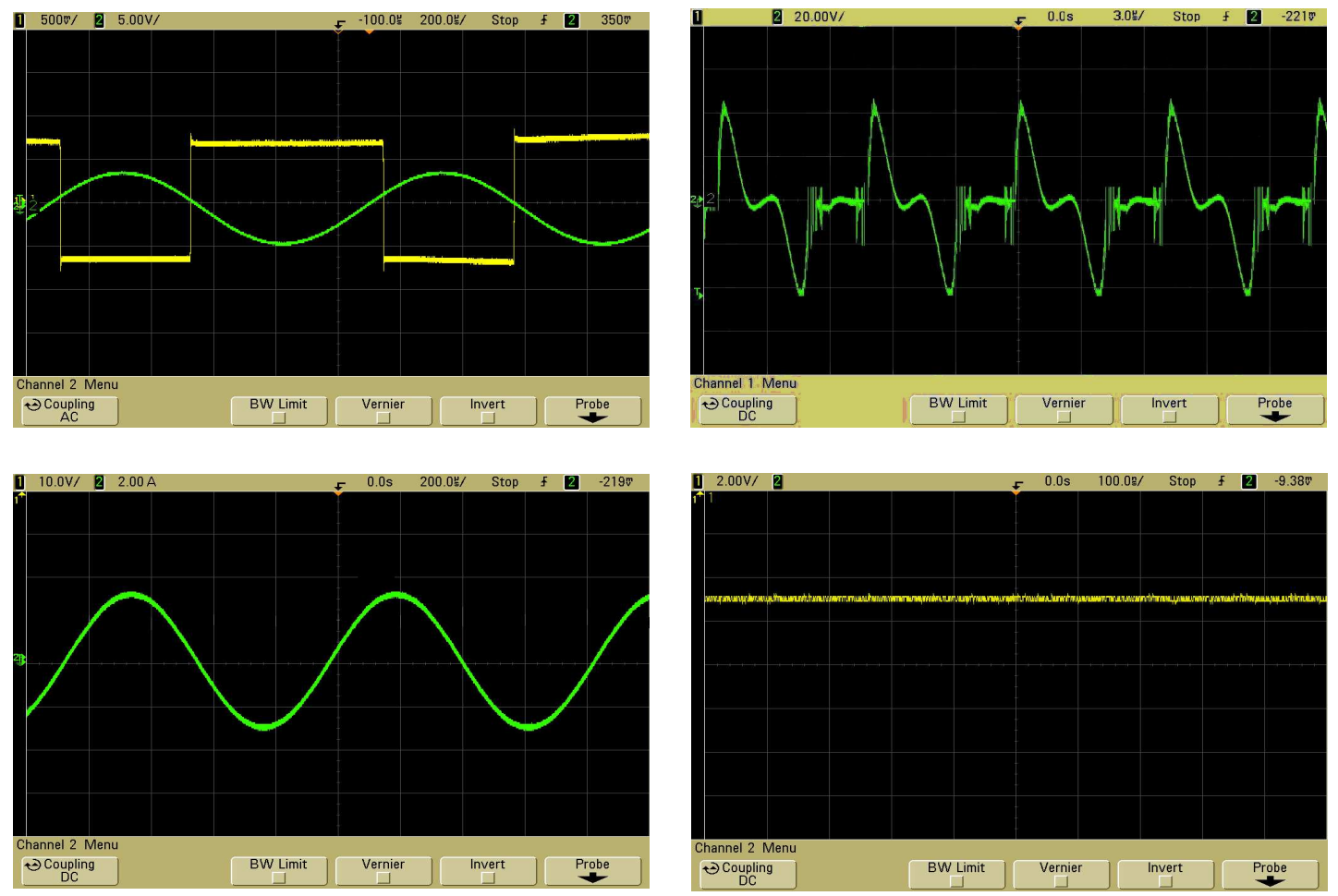

Fig. 7. Experimental waveforms for hardware module for CLL-T SPRC: (a) - CH1: resonant voltage (40 V/div), CH2: resonant current $(0.5 \mathrm{~A} / \mathrm{div}),(\mathrm{b})$ - voltage across the capacitor $(20 \mathrm{~V} / \mathrm{div}),(\mathrm{c})$ - current through series inductor $L_{1}(0.5 \mathrm{~A} / \mathrm{div})$, (d) - output capacitor voltage $(50 \mathrm{~V} /$ div $)$

integrator increases the system type number, thus minimizing the steady-state error. The additional phase delay introduced by the integrator tends to slow down the response. FLC help amplification of high frequency noise which is a serious drawback in switching converter applications. It is inferred that the measurement overshoot and noise is highly suppressed. The performance of CLL$\mathrm{T}$ converter response have been estimated and provided in Table 3. This ensures that the system can be controlled effectively with feedback.

It is clear from Table 3 that the peak overshoot is eliminated and the settling time is much lower with the fuzzy control strategy. The measurement noise is highly suppressed.

\subsection{Stability Studies for the Proposed Converter}

Figure 6(a) represents the stability investigation of the converter using the extended nyquist function technique. the stability is determined if $G(s) H(s)$ contour in the $G(s) H(s)$ plane corresponding to nyquist contour in $s$ plane encircles the point $-1+j 0$ in the anti-clockwise direction as many times as the number of right half $s$ plane poles of $G(s) H(s)$.then the closed loop system is stable. There is no encirclement of $-1+j 0$ point. This impels that the system is stable if there are no poles of $G(s) H(s)$ in the right half $s$-plane. If there are poles on right half $s$-plane then the system is unstable.

It is concluded that the CLL-T converter circuit is stable for the system parameters variations. It is observed 

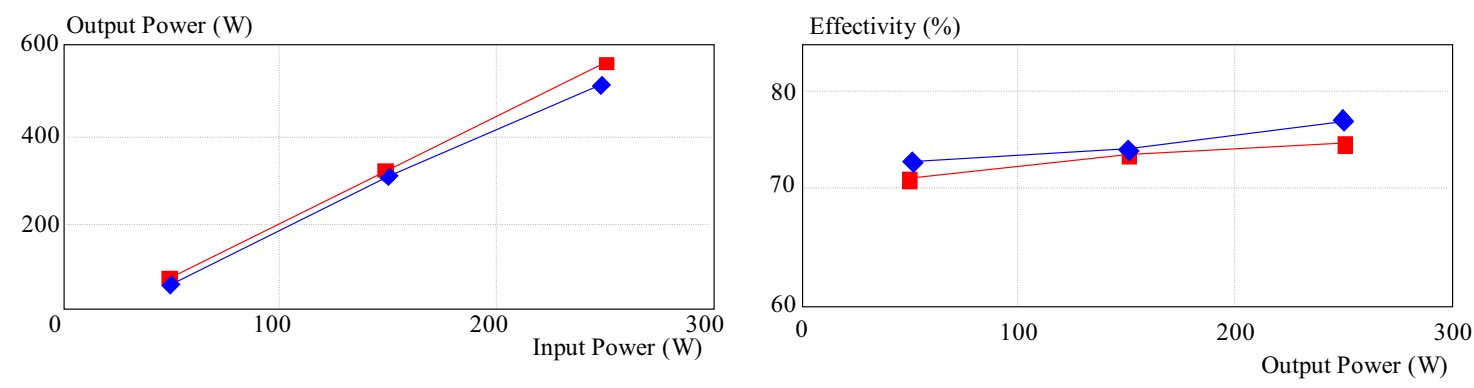

Fig. 8. Experimental results for (a) input power various with output power, (b) Output power various with efficiency

Table 4. Performance measures of Theoretical \& Simulink Results for CLL-T SPRC fed with RLE Load

\begin{tabular}{lcc}
\hline $\begin{array}{l}\text { Performance } \\
\text { measures }\end{array}$ & $\begin{array}{c}\text { Simulation } \\
\text { Studies }\end{array}$ & $\begin{array}{c}\text { Experimental } \\
\text { Studies }\end{array}$ \\
\hline Load Voltage in Volts & 99.8 & 94 \\
Load Current in Amps & 1.8 & 2.6 \\
Settling Time in millisecond & 0.01 & 1.4 \\
\% Over Shoot & 1 & 2.1 \\
Steady state error & 0.001 & 2.3 \\
\hline
\end{tabular}

that $-1+j 0$ point is encircled in the both directions in one time. Hence net encirclement is zero. Also the open loop system has no poles at the right half of $s$-plane.

\subsection{Converter analysis for the proposed con- verter}

Figure 6(b) shows the converter gain (M) versus frequency ratio $\left(\omega_{S} / \omega_{T}\right)$ characteristics for $\delta=1\left(L_{2} / L_{1}\right)$ and different values of $Q(0,0.5,1,1.5,2$ and 2.5$)$. The curve corresponding to $Q=0$ represents the no load characteristics. the no load gain $(M)$ depends on the frequency ratio, transformer turns ratio and $\delta$ from Fig. 6(b), it has been observed that the converter exhibits the load independent feature. Therefore, if the converter is designed to operate at or near the load independent point, then the output voltage can be controlled by a small change in operating frequency. This allows better utilization of the converter components. The frequency where the peak gain is obtained. The $Q$ decreases the gain value reaches to higher gain as well as the load decrease. The $Q$ increase the gain value reaches to $f_{r}$ as the load increases. Thus the full load condition should be the worst case for the resonant network design.

Figure $6(\mathrm{~b})$ shows the $\omega_{S} / \omega_{r}=1.15$ and shows the effect of secondary leakage. The peak gain at a given condition can be obtained by using the gain equation (4). It is difficult to express the peak gain in explicit form. The gain $(M)$ have error at frequency below the resonant frequency $\left(f_{r}\right)$ due to the fundamental approximation.

\section{EXPERIMENTAL RESULTS}

CLL-T SPRC is fabricated and tested. A prototype CLL-T SPRC is operating at $300 \mathrm{~W}, 100 \mathrm{kHz}$ was de- signed. ATMAL microcontroller 89C51 is used to generate driving pulses, these pulses are amplified using the driver IC IR2110, the IRF840 MOSFETs are used as the switches in the bridge converter. The diodes MUR 4100 are used for the output bridge rectifier. Its clearly shown in figures that the power losses in the occurrence of the turn on switching are maintained very low by means of the resonant operation. The hardware module is shown in Fig. 7. The Multi storage oscillogram (MSO) of Inverter voltage, inverter current, voltage across parallel capacitor, Current through inductance $L_{1}$ and Output voltage fed with the DC motor are shown in Figure. 7.

Figure 7 shows the fuzzy controller output signal for this test. These figures shows the good dynamic performance of the controller. Figure 7 (a) $\mathrm{CH} 1$ presents the inverter voltage, its measure from the point $\mathrm{A}$ and $\mathrm{B}$ of the bridge inverter. Figure 7(a) $\mathrm{CH} 2$ presents the resonant current, measured on the primary of the transformer. Figure 7(b). It can be seen that the peaks are relatively high, but an almost constant level is presented, which is assured by the primary converter controller. Figure $7(\mathrm{c})$. It can be seen from this figure that the current contains low harmonics and it presents a nearly sinusoidal shape. Figure $7(\mathrm{~d})$ shows the good performance of the whole design. One can conclude that the controller is capable of operating under load-independent operation, again, it can be seen that the output follows the reference with good accuracy and better dynamic performances. The CLL-T SPRC are verified by simulation and experimental studies. It is proved from the performance Table 4, the experimental results shows the control characteristics are observed to closely match the theoretical values, and the output voltage is seen to be nearly independent of load.

The output power for various input power and Output Power has been shown in Fig.8(a). It is absorbed that the power drawn decays steeply for lower load and as the load increases the power drawn gradually decreases and remain constant at greater loads. It is also seen that the proposed new control strategy has less load Sensitivity. The results obtained indicate that the FLC based CLL$\mathrm{T}$ SPRC is an effective approach for DC-DC converter output voltage regulation.

As shown in Figs. 8 (a)-(b).the control characteristics are observed to closely match the theoretical curve, and the output power is seen to be nearly independent of load. The conversion efficiency of the prototype is measured by varying the pulse to the inverter to vary the output power 
under different loading conditions at $100 \mathrm{~V}$ input dc voltage. The plots of experimental efficiency as a function of the output power are shown in Fig.8(b). The full load conversion efficiency of the prototype is measured to be 0.76 and it remains above 0.80 for $100300 \mathrm{~W}$ output power. Out of total $40 \mathrm{~W}$ power loss in the prototype operating at $300 \mathrm{~W}$, a major portion $(\approx 20 \mathrm{~W})$ is estimated to occur in the MOSFETs and diodes. The rest of losses can be attributed largely to the core and winding loss in transformer and resonant inductor.

\section{CONCLUSION}

The Stability analysis of CLL-T SPRC has been module and estimating the performance for various load conditions. This converter with a voltage type load and current type load shows it provides load independent operation. So, the switching power losses are minimized. It has been found from the simulated results that the closed loop controller provides better control strategies. A prototype $300 \mathrm{~W}, 100 \mathrm{kHz}$ converter was designed, the experiment results are compared with the simulation results. The simulation results agree with the experimental results. This modeling is expected to provide in depth concepts to the design engineers for various converter design required for verity of application.

\section{REFERENCES}

[1] BHAT, A. K. S.: Analysis and Design of A Fixed-frequency LCL-Type Series Resonant Converter with Capacitive Output Filter, IEE Proc-Circuits Devices Syst. 144 No. 2 (Apr 1997).

[2] RAJU, G. S. N.-DORADLA, S. : An LCL Resonant Converter with PWM Control Analysis, Simulation, and Implementation, IEEE Transactions on Power Electronics 10 No. 2 March 1995.

[3] BHAT, A. K. S.: Analysis and Design of LCL-Type Series Resonant Converter, IEEE INTELEC (1994), 172-178.

[4] BHAT, A. K. S.: Analysis and Design of a Series Parallel Resonant Converter, IEEE Trans. Power Electron 8 (Jan 1993), $1-11$.

[5] BORAGE, M. B.-NAGESH, K. V.-BHAtiA, M. S.-TIWARI, S.: Characteristics and Design of an Asymmetrical Duty-Cycle-Controlled LCL-T Resonant Converter, IEEE Transactions on Power Electronics 24 No. 10 (Oct 2009).

[6] BORAGE, M.-TIWARI, S.-KOTAIAH, S. : LCL-T Resonant Converter with Clamp Diodes: A Novel Constant-Current Power Supply With Inherent Constant-Voltage Limit, IEEE Transactions On Industrial Electronics 54 No. 2 (Apr 2007).

[7] BORAGE, M.-TIWARI, S.-KOTAIAH, S.: Analysis and Design of an LCL-T Resonant Converter as a Constant-Current Power Supply, IEEE Transactions on Industrial Electronics 52 No. 6 (Dec 2005).

[8] BELAGUli, V.-BHAT, A. K. S.: Series-Parallel Resonant Converter Operating in Discontinuous Current Mode-Analysis, Design, Simulation, and Experimental Results, IEEE Transactions on Circuits and System-I: Fundamental Theory and Applications 47 No. 4 (Apr 2000).

[9] CHINA, C. L.-ENG SNG, K. K.: A Novel Robust Control Method for the Series-Parallel Resonant Converter, IEEE Transactions on Power Electronics 24 No. 8 (Aug 2009).
[10] LAKSHMINARASAMMA, N.-MASIHUZZAMAN, M.-RAMANARAYANAN, V.: Steady State Stability of Current Mode Active Clamp ZVS DC-DC Converter, IEEE Transactions on Power Electronics 24 No. 10 (Oct 2009).

[11] FOSTER, M. P.-GOULD, C. R.-GILBERT, A. J.-STONE, D. A.-BINGHAM, C. M.: Analysis of CLL Voltage-Output Resonant Converters using Describing Function, IEEE Transactions on Power Electronics 23 No. 4 (July 2008).

[12] MAtTAVELli, P.-SPIAZZI, G.: General-Purpose Fuzzy Controller for DCDC Converters-jour IEEE Transactions on Power Electronics.

[13] CORREA, J. M.-FARRET, F. A.: A Fuzzy-Controlled Pulse Density Modulation Strategy for a Series Resonant Inverter with Wide Load Range, IEEE Transactions on Power Electronics 12 No. 1 (2003), 1650-1655.

[14] SIVAKUmARAN, T. S.-NATARAJAN, S. P.: Development of Fuzzy Control of Series-Parallel Loaded Resonant converter-Simulation and Experimental Evaluation, Proceedings of India International Conference on Power Electronics 2006, pp. 360-366.

[15] NAGARAJAN, C.-MADHESWARAN, M.: Performance Analysis of LCL-T Resonant Converter with Fuzzy/PID Controller using State Space Analysis, International Journal of Electronic Engineering Research 2 No. 1 (2010), 51-70.

16] PRABHAKAR, M.-ARULMAOZHI, S.-KAMARAJ, V.: Selection Criteria and Analysis of LCC Resonant DC-DC Converters for Automotive Application, Modern Applied Science 3 No. 7 (July 2009).

Received 21 January 2012

Chinnadurai Nagarajan received the BE degree from K.S. Rangasamy College of Technology, affiliated to Madras University, during 1997-2001, and the MTech degree from the Vellore Institute of Technology, Vellore, Tamilnadu India, in 2004. He obtained his $\mathrm{PhD}$ dgree in Power electroincs from Bharath Institute of Higher Education and Research (BIHER) University, Chennai, India. He has been a member of the faculty at Centre for Advanced Research, Muthayammal Engineering College, Rasipuram, Tamilnadu, India since 2005. His research interests include fuzzy logic and neural network applications to power electronics and drives.

Muthusamy Madheswaran received the BE Degree from Madurai Kamaraj University in 1990, ME Degree from Birla Institute of Technology, Mesra, Ranchi, India in 1992, both in Electronics and Communication Engineering. He obtained his $\mathrm{PhD}$ degree in Electronics Engineering from the Institute of Technology, Banaras Hindu University, Varanasi, India, in 1999. At present he is a principal of Muthayammal Engineering College, Rasipuram, India. He has authored over forty five research publications in international and national journals and conferences. His areas of interest are theoretical modeling and simulation of high-speed semiconductor devices for integrated optoelectronics application, Bio-optics and Biosignal Processing. He was awarded the Young Scientist Fellowship (YSF) by the State Council for Science and Technology, TamilNadu, in 1994 and Senior Research Fellowship (SRF) by the Council of Scientific and Industrial Research (CSIR), Government of India in 1996. Also he has received YSF from SERC, Department of Science and Technology, Govt. of India. He is named in Marquis Who's Who in Science and engineering in the year 2006. He is a life member of IETE, ISTE and IE (India) and also a senior member of IEEE. 